Prepared in cooperation with the National Oceanic and Atmospheric Administration

National Oceanic and Atmospheric Administration Hydrographic Survey Data Used in a U.S. Geological Survey Regional Geologic Framework Study Along the Delmarva Peninsula

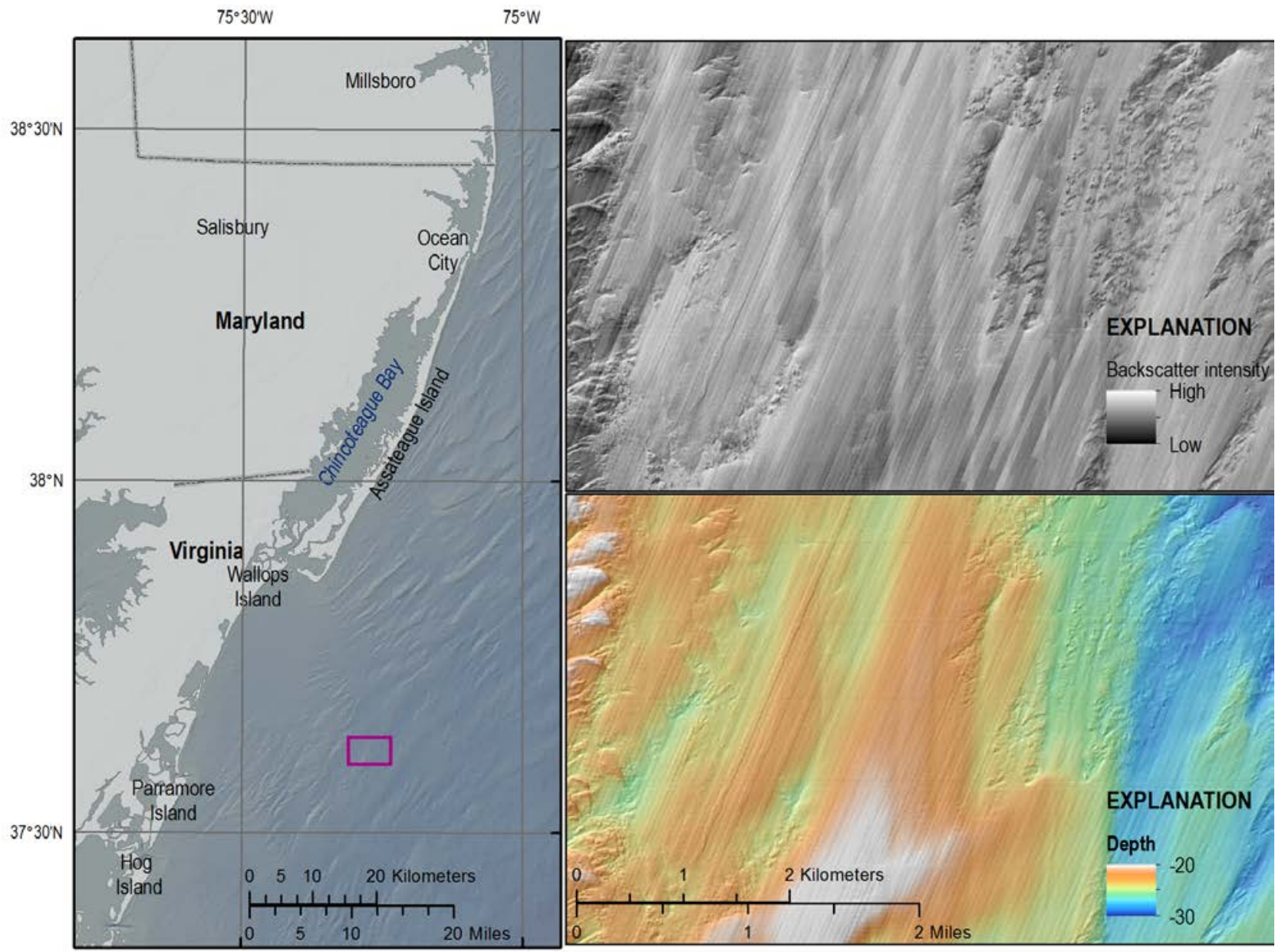

Open-File Report 2014-1262

U.S. Department of the Interior

U.S. Geological Survey 



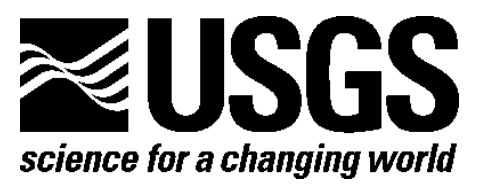

Prepared in cooperation with the National Oceanic and Atmospheric Administration

\section{National Oceanic and Atmospheric Administration Hydrographic Survey Data Used in a U.S. Geological Survey Regional Geologic Framework Study Along the Delmarva Peninsula}

By Elizabeth A. Pendleton, Laura L. Brothers, E. Robert Thieler, William W. Danforth, and Castle E. Parker

Open-File Report 2014-1262

U.S. Department of the Interior

U.S. Geological Survey 


\section{U.S. Department of the Interior SALLY JEWELL, Secretary}

\section{U.S. Geological Survey \\ Suzette M. Kimball, Acting Director}

U.S. Geological Survey, Reston, Virginia: 2015

For more information on the USGS-the Federal source for science about the Earth, its natural and living resources, natural hazards, and the environment-visit http://www.usgs.gov/ or call 1-888-ASK-USGS (1-888-275-8747).

For an overview of USGS information products, including maps, imagery, and publications, visit http://www.usgs.gov/pubprod/.

To order this and other USGS information products, visit http://store.usgs.gov/.

Any use of trade, firm, or product names is for descriptive purposes only and does not imply endorsement by the U.S. Government.

Although this information product, for the most part, is in the public domain, it also may contain copyrighted materials as noted in the text. Permission to reproduce copyrighted items must be secured from the copyright owner.

\section{Suggested citation:}

Pendleton, E.A., Brothers, L.L., Thieler, E.R., Danforth, W.W., and Parker, C.E., 2015, National Oceanic and Atmospheric Administration hydrographic survey data used in a U.S. Geological Survey regional geologic framework study along the Delmarva Peninsula: U.S. Geological Survey Open-File Report 2014-1262, 18 p., http://dx.doi.org/10.3133/ofr20141262. 


\section{Acknowledgments}

We thank David Rodziewicz (National Oceanic and Atmospheric Administration [NOAA] Corps), the National Ocean Service hydrographic data manager at the National Geophysical Data Center, Marine Geology and Geophysics Division, for providing the Reson raw data files for hydrographic surveys: H11647, H11648, H11649, H11872, H11873, H11874, H11992, H12001, H12002, H12003, and H12091. We thank Rebecca T. Quintal of Leidos (formerly SAIC) for providing, with NOAA's permission, Reson data files for hydrographic surveys H12092, H12093, H12094, H12160, H12161, H12336, H12337, H12338, and H12339. Both David and Rebecca were extremely helpful in communicating information and providing data to aid this effort, and we sincerely wish to thank them for their patience and cooperation.

We also wish to thank Anya Duxfield and the Fledermaus software support and development team at Quality Positioning Service for their dedication to providing support and solutions to the users of Fledermaus FMGeocoder Toolbox software.

Andrea Toran of the U.S. Geological Survey (USGS) provided essential support and guidance during the publication of this report. This report also benefited from reviews by Larry Poppe, Jane Denny, and VeeAnn Cross (all of the USGS). 


\section{Contents}

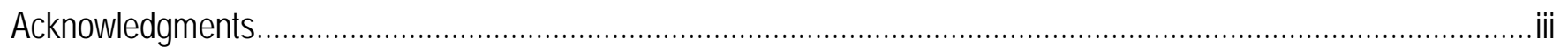

Abstract …… - w w

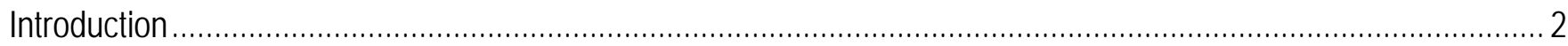

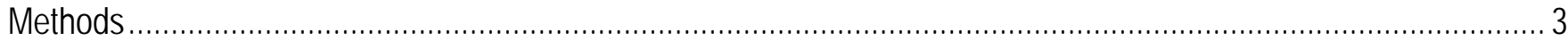

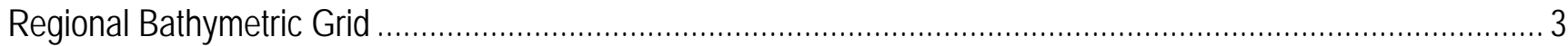

Regional Multibeam Backscatter Mosaic ............................................................................................... 3

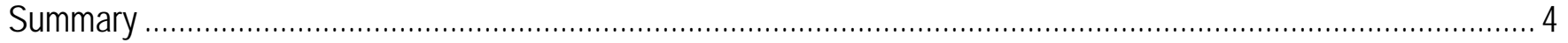

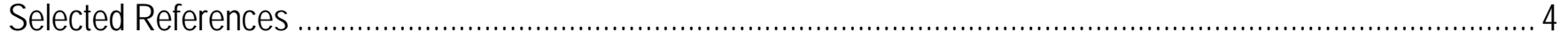

\section{Figures}

1. Map of the Delmarva Peninsula, Delaware, Maryland, and Virginia, showing the 23 hydrographic surveys used to create the regional bathymetric grid and backscatter mosaic

2. Map showing nine hydrographic surveys along the Delmarva Peninsula, Delaware, Maryland, and Virginia, that used Klein sidescan sonar between 2006 and 2009 to produce mosaics along with bathymetric data .. 9

3. Maps of gridded bathymetric data from National Oceanic and Atmospheric Administration survey H12003 along the Delmarva Peninsula, Delaware, Maryland, and Virginia 10

4. Map of resampled, interpolated bathymetric data from National Oceanic and Atmospheric Administration surveys H12003, H12092, H12093, and H12094 along the Delmarva Peninsula, Delaware, Maryland, and Virginia............................................................................................................................... 11

5. Map showing the interpolated bathymetric data along the Delmarva Peninsula, Delaware, Maryland, and Virginia, in a 5-meter-per-pixel grid ............................................................................................ 12

6. Map of National Oceanic and Atmospheric Administration survey H11647 along the Delmarva Peninsula, Delaware, Maryland, and Virginia ............................................................................................ 13

7. Map of National Oceanic and Atmospheric Administration survey H12160 along the Delmarva Peninsula, Delaware, Maryland, and Virginia 14

8. Map showing 2-meter-per-pixel resolution multibeam backscatter images for 20 hydrographic surveys along the Delmarva Peninsula, Delaware, Maryland, and Virginia ....................................................... 15

9. Images of acoustic backscatter mosaics from National Oceanic and Atmospheric Administration survey H12003 along the Delmarva Peninsula, Delaware, Maryland, and Virginia ............................................. 16

\section{Tables}

1. National Oceanic and Atmospheric Administration hydrographic surveys along the Delmarva Peninsula, Delaware, Maryland, and Virginia, processed for multibeam backscatter. 17

2. Advantages and disadvantages of multibeam echosounder and sidescan sonar backscatter. 


\section{Conversion Factors}

International System of Units to Inch/Pound

\begin{tabular}{lcll}
\hline & Multiply & & To obtain \\
\hline & Length & & \\
\hline centimeter $(\mathrm{cm})$ & 0.3937 & inch (in.) \\
meter $(\mathrm{m})$ & 3.281 & foot $(\mathrm{ft})$ \\
kilometer $(\mathrm{km})$ & 0.6214 & mile (mi) & \\
kilometer $(\mathrm{km})$ & 0.5400 & mile, nautical (nmi) & \\
\hline & Area & \\
\hline square meter $\left(\mathrm{m}^{2}\right)$ & 10.76 & square foot $\left(\mathrm{ft}^{2}\right)$ \\
square kilometer $\left(\mathrm{km}^{2}\right)$ & 0.3861 & square mile $\left(\mathrm{mi}^{2}\right)$ & \\
\hline
\end{tabular}

\section{Datum}

Vertical coordinate information is referenced to the Mean Lower Low Water (MLLW) tidal datum.

Horizontal coordinate information is referenced to the World Geodetic Coordinate System of 1984 (WGS 84).

\section{Abbreviations}

$\begin{array}{ll}\text { BAG } & \text { bathymetry attributed grid } \\ \text { FMGT } & \text { FMGeocoder Toolbox Fledermouse module } \\ \text { GIS } & \text { geographic information system } \\ \text { GeoPDF } & \text { georeferenced portable document formation } \\ \text { GeoTIFF } & \text { georeferenced tagged interface file format } \\ \text { GSF } & \text { generic sensor format } \\ \text { MBES } & \text { multibeam echosounders } \\ \text { MN } & \text { motor vessel } \\ \text { NOAA } & \text { National Oceanic and Atmospheric Administration } \\ \text { NOS } & \text { National Ocean Service } \\ \text { SAIC } & \text { Science Applications International Corporation } \\ \text { USGS } & \text { U.S. Geological Survey }\end{array}$





\title{
National Oceanic and Atmospheric Administration Hydrographic Survey Data Used in a U.S. Geological Survey Regional Geologic Framework Study Along the Delmarva Peninsula
}

\author{
By Elizabeth A. Pendleton, ${ }^{1}$ Laura L. Brothers, ${ }^{1}$ E. Robert Thieler, ${ }^{1}$ William W. Danforth, ${ }^{1}$ and Castle E. Parker ${ }^{2}$
}

\begin{abstract}
The U.S. Geological Survey initiated a research effort in 2014 to define the geologic framework of the Delmarva Peninsula inner continental shelf, which included new data collection and assembly of relevant extant datasets. Between 2006 and 2011, Science Applications International Corporation, under contract to the National Oceanic and Atmospheric Administration National Ocean Service, carried out 23 hydrographic surveys covering more than 4,100 square kilometers of the continental shelf using Reson multibeam echosounders and Klein towed sidescan sonars to update nautical charts along the Delmarva Peninsula. Acoustic backscatter data from these instruments are valuable for characterizing aspects of shallow geologic framework, including seafloor geology, sediment transport pathways, and marine resources. The data cover an area that extends from the entrance of Delaware Bay, Delaware, south to Parramore Island, Virginia, in water depths of about 3 to 35 meters below mean lower low water. Data were collected along lines spaced 40 meters apart, resulting in 40 to 100 percent seafloor coverage for multibeam bathymetry. Processed bathymetric data within the Delmarva Peninsula study area are available through a National Ocean Service interactive map interface, but towed sidescan data products are limited, and multibeam backscatter data products have not been available in the past.

The U.S. Geological Survey obtained raw Reson multibeam data files from Science Applications International Corporation and the National Oceanic and Atmospheric Administration for 20 hydrographic surveys and extracted backscatter data using the Fledermaus Geocoder Toolbox from Quality Positioning Service. The backscatter mosaics produced by the U.S. Geological Survey for the inner continental shelf of the Delmarva Peninsula using National Oceanic and Atmospheric Administration data increased regional geophysical surveying efficiency, collaboration among government agencies, and the area over which geologic data can be interpreted by the U.S. Geological Survey. This report describes the methods by which the backscatter data were extracted and processed and includes backscatter mosaics and interpolated bathymetric surfaces.
\end{abstract}

\footnotetext{
${ }^{1}$ U.S. Geological Survey

${ }^{2}$ National Oceanic and Atmospheric Administration
} 


\section{Introduction}

In 2014, the U.S. Geological Survey (USGS) began a collaborative project with the University of Delaware, the National Park Service, the Mid-Atlantic Coastal Resilience Institute, and the National Oceanographic and Atmospheric Administration (NOAA) to define the geologic framework of the Delmarva Peninsula coastal system. Geologic mapping of the inner continental shelf combined with oceanographic processes data are intended to be used to facilitate effective management of this dynamic coastal system as it responds to storms, sea-level rise, and anthropogenic activities. This mapping effort builds on recent and ongoing hydrographic, geologic, and ecological studies in the area and represents a unique opportunity to construct a geospatial framework around existing datasets and to acquire new data to fill knowledge gaps. This report presents an existing hydrographic dataset collected by Science Applications International Corporation (SAIC) under contract to NOAA's National Ocean Service (NOS) and reprocessed by the USGS to extract backscatter and generate seamless bathymetric and backscatter surfaces for the region. Prior to recent software advances, multibeam backscatter datasets were too cumbersome to extract and use. This report describes a technique that uses recently developed software to reprocess the NOAA dataset. The dataset as reprocessed by the USGS provides valuable baseline geophysical information that enhances our understanding of seafloor geology and sediment transport pathways within the Delmarva coastal system.

Between 2006 and 2011, NOAA carried out 23 hydrographic surveys covering more than 4,100 square kilometers of the Atlantic inner shelf adjacent to the Delmarva Peninsula. Reson multibeam echosounders (MBESs) and Klein sidescan sonars were used to collect data aboard the motor vessel (M/V) Atlantic Surveyor for the purposes of updating nautical charts (fig. 1; table 1). The survey area extended from the entrance of Delaware Bay offshore of Cape Henlopen, Delaware, to the south past Parramore Island, Virginia, in water depths from about 3 to 35 meters (m) below mean lower low water (fig. 1). MBES bathymetry and backscatter were acquired using a Reson Seabat 8101 between 2006 and 2009 and a Reson Seabat 7125 between 2010 and 2011. Sidescan sonar data were collected with a Klein 3000 dual frequency sonar. The Reson MBES bathymetric and backscatter data are the focus of this report. Trackline spacing was set at $40 \mathrm{~m}$ for all 23 of the hydrographic surveys, producing full seafloor coverage in water depths greater than $10 \mathrm{~m}$ and between 40 and 100 percent coverage in water depths less than $10 \mathrm{~m}$.

NOAA published the processed Reson bathymetry for all 23 hydrographic surveys in bathymetry attributed grid (BAG) format files at resolutions from 50 centimeters per pixel to 4 meters per pixel. Klein sidescan sonar mosaics were published as georeferenced tagged image file formats (GeoTIFFs) from three of the surveys and as layers in georeferenced portable document format (GeoPDF) maps from six other surveys (fig. 2; table 1). The bathymetric and sidescan data are available on the National Geophysical Data Center's (NGDC) Interactive Mapping Server (IMS) Web interface (http://maps.ngdc.noaa.gov/viewers/bathymetry/). Multibeam BAG files were downloaded from the IMS for each survey, interpolated to fill gaps, then combined (mosaicked) at 5-meter-per-pixel resolution. In order to create a continuous backscatter mosaic for the seafloor in the surveyed area, the USGS obtained the raw Reson data in generic sensor format (GSF) from NOAA and SAIC for 20 surveys to process for backscatter. 


\section{Methods}

\section{Regional Bathymetric Grid}

More than 40 BAG files were downloaded from the NGDC's IMS at resolutions between 50 centimeters per pixel and 4 meters per pixel. Due to the set 40-m track line spacing, seafloor coverage was less than 100 percent in water depths less than $10 \mathrm{~m}$ (fig. 3). Each BAG file was imported into Quality Positioning Service’s (QPS) Fledermaus software and converted to scientific data [object] (.sd) format. Individual .sd files within surveys were then merged using the surfacemerge function in Fledermaus's FMCommand utility. The merged .sd files were then interpolated for five iterations using the Fledermaus "interpolate surface" function to fill gaps in shallow-water areas. Despite five iterations, gaps remain in the regional bathymetric grid across three shoal areas in the vicinity of Chincoteague Inlet Va., where the M/V Atlantic Surveyor could not survey due to draft restrictions (fig. 4). These gaps were left unfilled in order to avoid introducing erroneous depth values through interpolation. Merged, interpolated 32-bit GeoTIFFs for each survey were exported from Fledermaus and loaded into Esri ArcMap where they were resampled to 5-meter-per-pixel resolution and mosaicked into a single raster dataset (fig. 5).

\section{Regional Multibeam Backscatter Mosaic}

In 2005, the University of New Hampshire developed GeoCoder software to improve multibeam backscatter processing (Rzhanov and others, 2011). GeoCoder backscatter processing algorithms are now part of several hydro-industry software packages. In this report, QPS Fledermaus FMGeocoder Toolbox (FMGT) version 7.4.1 was used to process all GSF format Reson data obtained from NOAA and SAIC. The relative ease with which multibeam backscatter can now be processed gives multibeam backscatter some advantages over sidescan sonar backscatter. However, the broader swath width of a sidescan sonar compared with the swath width of MBES can be a surveying time advantage in areas where full multibeam seafloor coverage is not required (table 2).

The survey data obtained from NOAA and SAIC contained only beam-average backscatter data, meaning that 'snippets' or time series backscatter data were not recorded. Beam-average data can still produce high-quality backscatter imagery, especially for regional-scale geologic mapping purposes. Geoscientists prefer snippet data, when available, because they offer the full time series of decibel (dB) values and thus a more dynamic range in a final backscatter mosaic when compared with beam-average data. Snippet data files, however, can be prohibitively large to archive because the full dB time series results in raw data files that are several times larger than files without snippet data. SAIC did not archive multibeam backscatter snippets because NOAA's charting mission was fulfilled by the collection of multibeam bathymetry, including more than 200 percent seafloor coverage with sidescan sonar data.

Hydrographic surveys were processed individually in FMGT to allow modification of processing parameters among surveys (such as ocean absorption coefficients). In most cases, the data were processed as beam-average Reson 8101 or 7125 backscatter data on a per survey basis. The metadata included in the Data Download section of this report provide more detailed information on processing parameters.

All of the 20 Reson surveys for which GSF data were obtained produced useable backscatter mosaics, though there was some variation in mosaic quality. With the help of the software support and development team at QPS, issues encountered during processing were resolved. One issue noted in the 
Reson 7125 data from 2010 and 2011 was resolved by QPS under a new software release (version 7.4.1). In general, among the surveys where sidescan sonar mosaics are available for comparison with multibeam backscatter mosaics, both the Reson 8101 and the Reson 7125 produced backscatter mosaics of quality comparable to the Klein sidescan sonar mosaics (figs. 6 and 7). Some mosaics contain banding artifacts from incremental gain changes during acquisition, but the banding does not appear to obscure seafloor features in the final 2-meter-per-pixel resolution backscatter mosaics. After satisfactory mosaic images for each survey were produced with FMGT, mosaics were exported as 2-meter-per-pixel resolution GeoTIFF images (fig. 8). MathWorks's MATLAB was used to fill gaps between adjacent lines in shallow water (less than 8 to $10 \mathrm{~m}$ deep) and other small data drop out areas in the mosaics by interpolating backscatter values from surrounding pixels to replace pixels with null values using an inverse distance-weighted method. Surveys at an average depth greater than $10 \mathrm{~m}$ required minimal interpolation. More interpolation was required in some of the nearshore surveys where mean water depths were less than $10 \mathrm{~m}$ and seafloor coverage was less than 100 percent (fig. 9).

\section{Summary}

A seamless regional 5-meter-per-pixel bathymetric grid (fig. 5) and 2-meter-per-pixel resolution backscatter mosaic images (fig. 8) for the inner continental shelf from Cape Henlopen, Delaware, to Parramore Island, Virginia, were created from hydrographic survey data collected by Science Applications International Corporation and the National Oceanic and Atmospheric Administration (NOAA) National Ocean Service (NOS). These data were collected by NOAA at high resolution and high density to update navigational charts and identify navigational hazards along the coast of the Delmarva Peninsula. The U.S. Geological Survey (USGS) reprocessed and resampled the data to aid a regional-scale geologic framework study of the Delmarva Peninsula, which aims to facilitate our understanding and effective management of this dynamic coastal system as it responds to storms, sealevel rise, and anthropogenic activities.

This study is an example of interagency collaboration and demonstrates that one dataset can serve the missions of two agencies. Although NOAA and the USGS often partner to conduct research and create geologic data products from hydrographic survey information (for example, Andrews and others, 2013; Poppe and others, 2014), this study is unique in that the backscatter data products are derived from multibeam echosounder (MBES) data, which have historically been underutilized as a geophysical dataset until the availability of software that can efficiently process large volumes of MBES backscatter data. This study suggests that similar NOAA datasets could be reprocessed and repurposed for geologic investigations in the future. Such collaborations optimize government investments in marine research.

\section{Selected References}

Andrews, B.D., Chaytor, J.D., ten Brink, U.S., Brothers, D.S., and Gardner, J.V., 2013, Bathymetric terrain model of the Atlantic Margin for marine geological investigations: U.S. Geological Survey Open-File Report 2012-1266, 11 p., accessed September 12, 2014, at http://dx.doi.org/10.3133/ofr20121266.

Hewitt, Anthony, Salisbury, Richard, and Wilson, Jerry, 2010, Using multibeam echosounder backscatter to characterize seafloor features-Geocoder processing gives multibeam echosounder backscatter an advantage over side scan sonar in producing reliable seafloor maps: Sea Technology, 
v. 51, no. 9, accessed July 23, 2014, at http://www.sea-

technology.com/features/2010/0910/multibeam_echosounder_backscatter.php.

National Oceanic and Atmospheric Administration, 2006a, Survey H11554-Multibeam and side scan sonar descriptive report: National Oceanic and Atmospheric Administration SAIC Doc. 06-TR-015, 13 p., accessed September 12, 2014, at http://surveys.ngdc.noaa.gov/mgg/NOS/coast/H10001H12000/H11554/DR/H11554.pdf.

National Oceanic and Atmospheric Administration, 2006b, Survey H11555-Multibeam and side scan sonar descriptive report: National Oceanic and Atmospheric Administration SAIC Doc. 06-TR-016, 57 p., accessed September 12, 2014, at http://surveys.ngdc.noaa.gov/mgg/NOS/coast/H10001H12000/H11555/DR/H11555.pdf.

National Oceanic and Atmospheric Administration, 2007a, Survey H11650_Multibeam and sidescan sonar descriptive report: National Oceanic and Atmospheric Administration SAIC Doc. 07-TR-011, 18 p. plus appendixes, accessed September 12, 2014, at http://surveys.ngdc.noaa.gov/mgg/NOS/coast/H10001-H12000/H11650/DR/H11650.pdf.

National Oceanic and Atmospheric Administration, 2007b, Survey H11647-Multibeam and sidescan sonar descriptive report: National Oceanic and Atmospheric Administration SAIC Doc. 07-TR-008, 164 p., accessed September 12, 2014, at http://surveys.ngdc.noaa.gov/mgg/NOS/coast/H10001H12000/H11647/DR/H11647.pdf.

National Oceanic and Atmospheric Administration, 2007c, Survey H11648-Multibeam and sidescan sonar descriptive report: OPR-D302-KR-07: National Oceanic and Atmospheric Administration SAIC Doc. 07-TR-009, 167 p, accessed September 12, 2014, at http://surveys.ngdc.noaa.gov/mgg/NOS/coast/H10001-H12000/H11648/DR/H11648.pdf.

National Oceanic and Atmospheric Administration, 2007d, Survey H11649-Multibeam and sidescan sonar descriptive report: National Oceanic and Atmospheric Administration SAIC Doc. 07-TR-010, 77 p., accessed September 12, 2014, at http://surveys.ngdc.noaa.gov/mgg/NOS/coast/H10001H12000/H11649/DR/H11649.pdf.

National Oceanic and Atmospheric Administration, 2008a, Survey H11872-Multibeam and sidescan sonar descriptive report: National Oceanic and Atmospheric Administration SAIC Doc. 09-TR-035, 34 p. plus appendixes, accessed September 12, 2014, at http://surveys.ngdc.noaa.gov/mgg/NOS/coast/H10001-H12000/H11872/DR/H11872.pdf.

National Oceanic and Atmospheric Administration, 2008b, Survey H11873-Multibeam and sidescan sonar descriptive report: National Oceanic and Atmospheric Administration SAIC Doc. 09-TR-043, 32 p. plus appendixes, accessed September 12, 2014, at http://surveys.ngdc.noaa.gov/mgg/NOS/coast/H10001-H12000/H11873/DR/H11873.pdf.

National Oceanic and Atmospheric Administration, 2008c, Survey H11992-Multibeam and sidescan sonar descriptive report: National Oceanic and Atmospheric Administration SAIC Doc. 09-TR-045, 19 p. plus appendixes, accessed September 12, 2014, at http://surveys.ngdc.noaa.gov/mgg/NOS/coast/H10001-H12000/H11992/DR/H11992.pdf.

National Oceanic and Atmospheric Administration, 2008d, Survey H11874-Multibeam and sidescan sonar descriptive report: National Oceanic and Atmospheric Administration SAIC Doc. 09-TR-044, 24 p. plus appendixes, accessed September 12, 2014, at http://surveys.ngdc.noaa.gov/mgg/NOS/coast/H10001-H12000/H11874/DR/H11874.pdf.

National Oceanic and Atmospheric Administration, 2009, Survey H12001-Multibeam and sidescan sonar descriptive report: National Oceanic and Atmospheric Administration SAIC Doc. 10-TR-001, 20 p. plus appendixes, accessed September 12, 2014, at http://surveys.ngdc.noaa.gov/mgg/NOS/coast/H12001-H14000/H12001/DR/H12001.pdf. 
National Oceanic and Atmospheric Administration, 2010a, Survey H12093-Multibeam and sidescan sonar descriptive report: National Oceanic and Atmospheric Administration SAIC Doc. 11-TR-001, 35 p. plus appendixes, accessed September 12, 2014, at http://surveys.ngdc.noaa.gov/mgg/NOS/coast/H12001-H14000/H12093/DR/H12093.pdf.

National Oceanic and Atmospheric Administration, 2010b, Survey H12094-Multibeam and sidescan sonar descriptive report: National Oceanic and Atmospheric Administration SAIC Doc. 10-TR-040, 41 p. plus appendixes, accessed September 12, 2014, at http://surveys.ngdc.noaa.gov/mgg/NOS/coast/H12001-H14000/H12094/DR/H12094.pdf.

National Oceanic and Atmospheric Administration, 2010c, Survey H12160-Multibeam and sidescan sonar descriptive report: National Oceanic and Atmospheric Administration SAIC Doc. 11-TR-003, 26 p. plus appendixes, accessed September 12, 2014, at http://surveys.ngdc.noaa.gov/mgg/NOS/coast/H12001-H14000/H12161/DR/H12161.pdf.

National Oceanic and Atmospheric Administration, 2010d, Survey H12002-Multibeam and sidescan sonar descriptive report: National Oceanic and Atmospheric Administration SAIC Doc. 10-TR-002, 74 p., accessed September 12, 2014, at http://surveys.ngdc.noaa.gov/mgg/NOS/coast/H12001H14000/H12002/DR/H12002.pdf.

National Oceanic and Atmospheric Administration, 2010e, Survey H12003-Multibeam and sidescan sonar descriptive report: National Oceanic and Atmospheric Administration SAIC Doc. 10-TR-003, 31 p. plus appendixes, accessed September 12, 2014, at http://surveys.ngdc.noaa.gov/mgg/NOS/coast/H12001-H14000/H12003/DR/H12003.pdf.

National Oceanic and Atmospheric Administration, 2010f, Survey H12091-Multibeam and sidescan sonar descriptive report: National Oceanic and Atmospheric Administration SAIC Doc. 10-TR-004, 26 p. plus appendixes, accessed September 12, 2014, at http://surveys.ngdc.noaa.gov/mgg/NOS/coast/H12001-H14000/H12091/DR/H12091.pdf.

National Oceanic and Atmospheric Administration, 2010g, Survey H12092-Multibeam and sidescan sonar descriptive report: National Oceanic and Atmospheric Administration SAIC Doc. 10-TR-030, 41 p. plus appendixes, accessed September 12, 2014, at http://surveys.ngdc.noaa.gov/mgg/NOS/coast/H12001-H14000/H12092/DR/H12092.pdf.

National Oceanic and Atmospheric Administration, 2011a, Survey H12336-Multibeam and sidescan sonar descriptive report: National Oceanic and Atmospheric Administration SAIC Doc. 11-TR-030, 29 p. plus appendixes, accessed September 12, 2014, at http://surveys.ngdc.noaa.gov/mgg/NOS/coast/H12001-H14000/H12336/DR/H12336.pdf.

National Oceanic and Atmospheric Administration, 2011b, Survey H12337-Multibeam and sidescan sonar descriptive report: National Oceanic and Atmospheric Administration SAIC Doc. 12-TR-003, 29 p. plus appendixes, accessed September 12, 2014, at http://surveys.ngdc.noaa.gov/mgg/NOS/coast/H12001-H14000/H12337/DR/H12337.pdf.

National Oceanic and Atmospheric Administration, 2011c, Survey H12339-Multibeam and sidescan sonar descriptive report: National Oceanic and Atmospheric Administration SAIC Doc. 12-TR-005, 33 p. plus appendixes, accessed September 12, 2014, at http://surveys.ngdc.noaa.gov/mgg/NOS/coast/H12001-H14000/H12339/DR/H12339.pdf.

National Oceanic and Atmospheric Administration, 2011d, Survey H12160-Multibeam and sidescan sonar descriptive report: National Oceanic and Atmospheric Administration SAIC Doc. 11-TR-005, 27 p. plus appendixes, accessed September 12, 2014, at http://surveys.ngdc.noaa.gov/mgg/NOS/coast/H12001-H14000/H12160/DR/H12160.pdf.

National Oceanic and Atmospheric Administration, 2011e, Survey H12338-Multibeam and sidescan sonar descriptive report: National Oceanic and Atmospheric Administration SAIC Doc. 12-TR-004, 
33 p. plus appendixes, accessed September 12, 2014, at http://surveys.ngdc.noaa.gov/mgg/NOS/coast/H12001-H14000/H12338/DR/H12338.pdf.

Poppe, L.J., McMullen, K.Y., Danforth, W.W., Blankenship, M.A., Clos, A.R., Glomb, K.A., Lewit, P.G., Nadeau, M.A., Wood, D.A., and Parker, C.E., 2014, Combined multibeam bathymetry data from Rhode Island Sound and Block Island Sound-A regional perspective: U.S. Geological Survey OpenFile Report 2014-1012, DVD-ROM, accessed September 12, 2014, at http://dx.doi.org/10.3133/ofr20141012.

Rzhanov, Yuri, Fonseca, Luciano, and Mayer, Larry, 2011, Construction of seafloor thematic maps from multibeam acoustic backscatter angular response data: Computers and Geosciences Journal, v. 41, p. 181-187. [Also available at http://dx.doi.org/10.1016/j.cageo.2011.09.001.] 


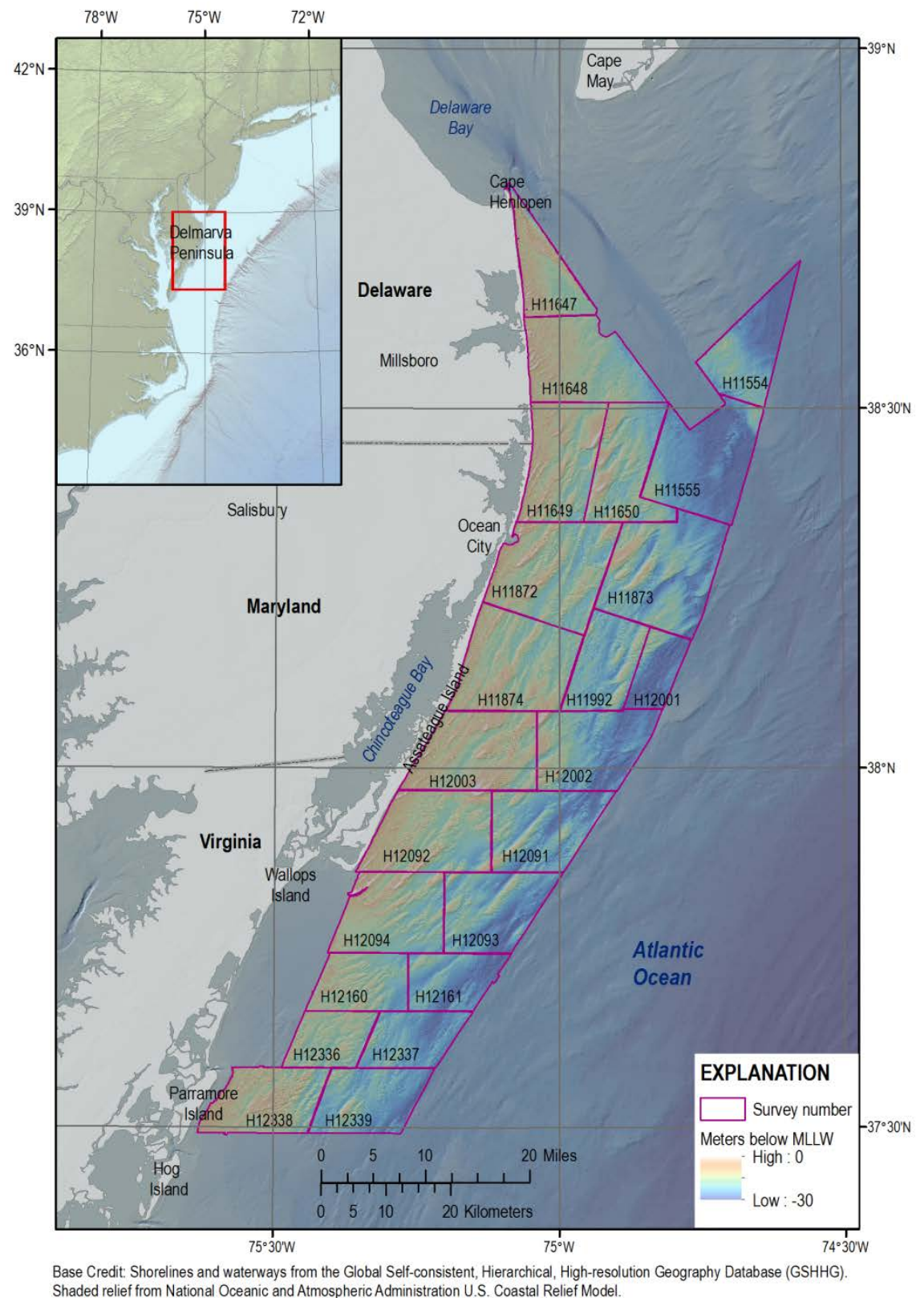

Figure 1. Map of the Delmarva Peninsula, Delaware, Maryland, and Virginia, showing the 23 hydrographic surveys used to create the regional bathymetric grid and backscatter mosaic. The survey boundaries and numbers are shown along with the multibeam bathymetric data that were collected simultaneously with backscatter using Reson 8101 and Reson 7125 systems. Details of the hydrographic surveys are listed in table 1. MLLW; mean lower low water. Not for navigational use. 


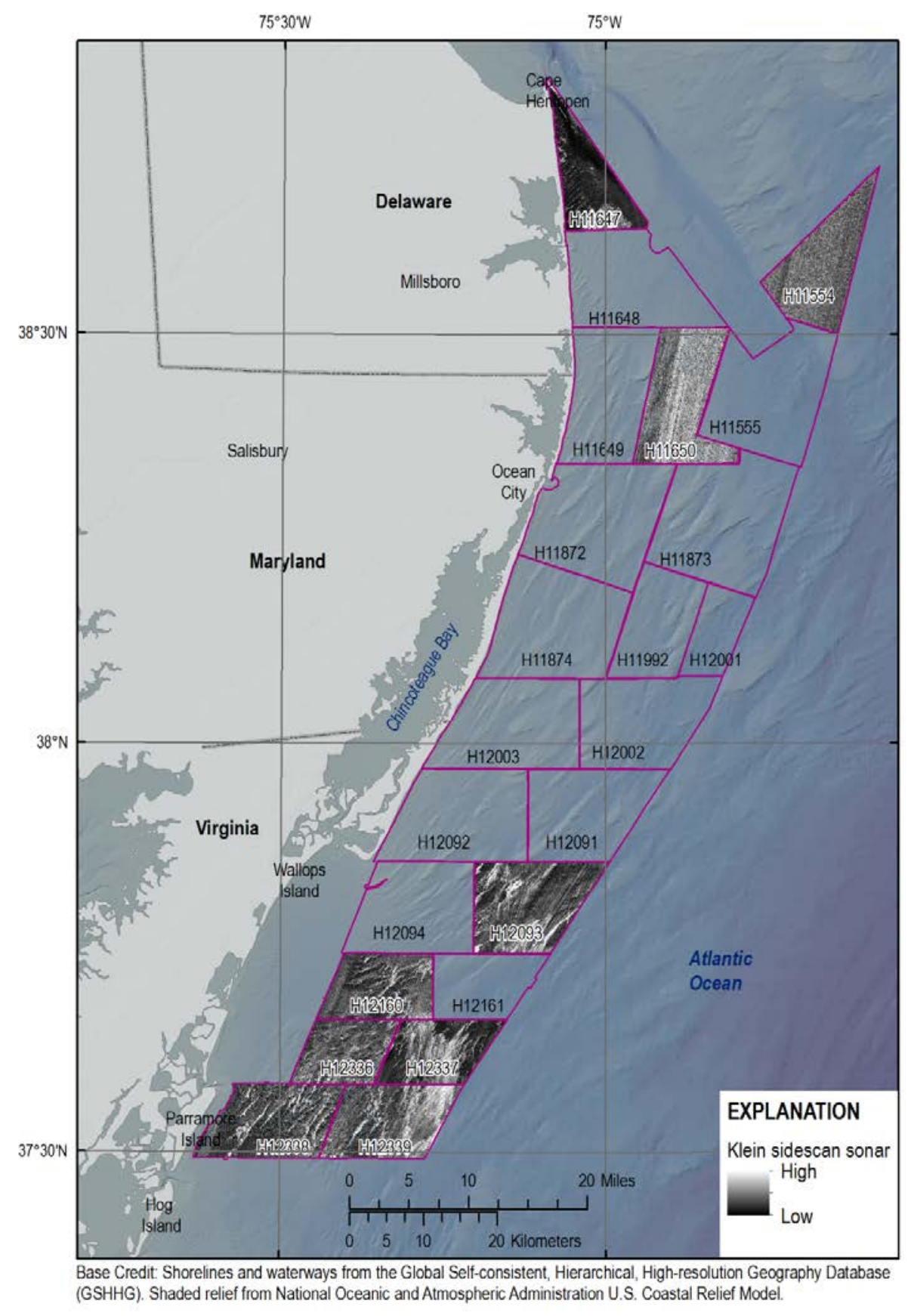

Figure 2. Map showing nine hydrographic surveys along the Delmarva Peninsula, Delaware, Maryland, and Virginia, that used Klein sidescan sonar to produce mosaics along with bathymetric data. Details of the hydrographic surveys are listed in table 1 . Not for navigational use. Other sidescan mosaics may be available by request through NOAA. 


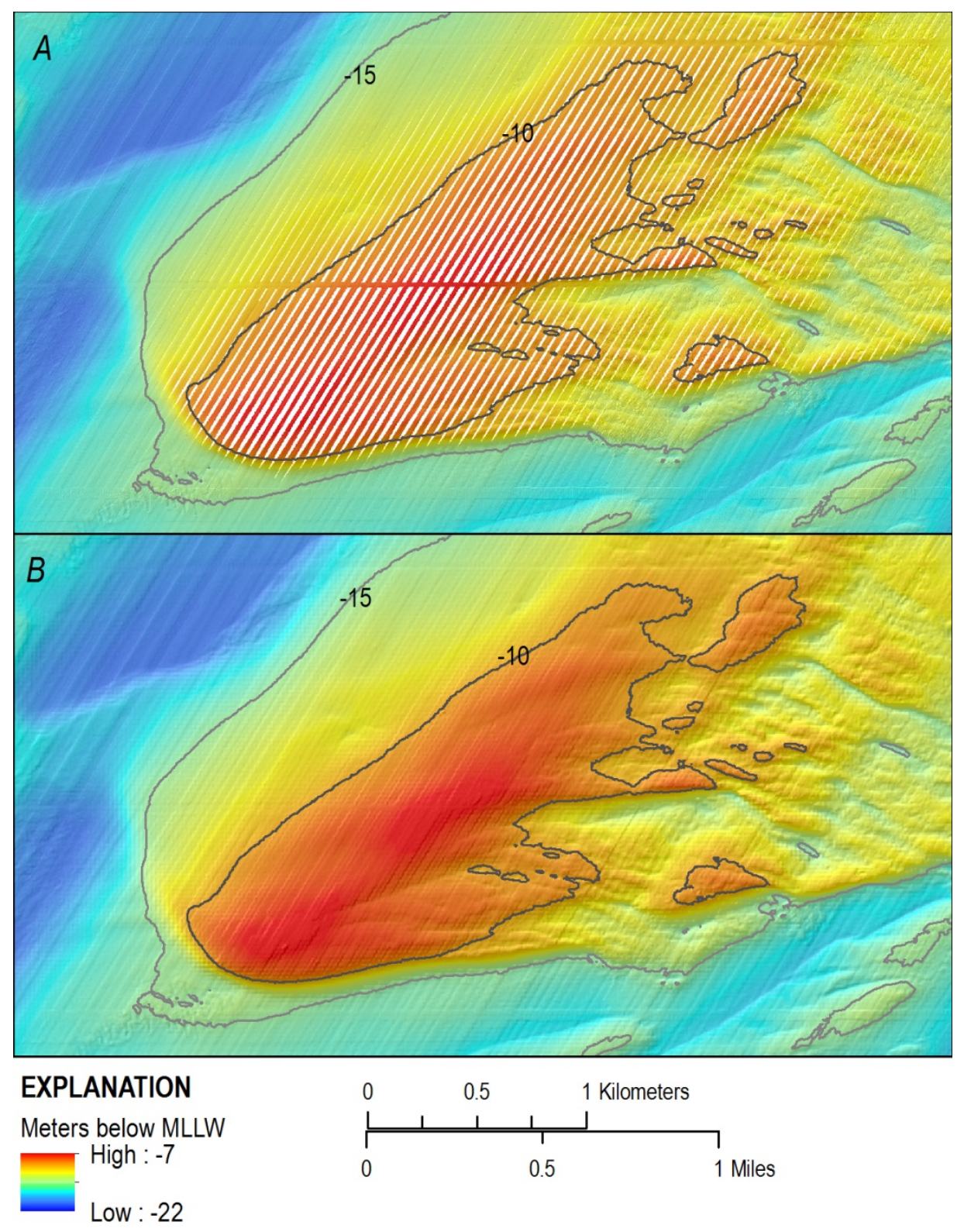

Figure 3. Maps of gridded bathymetric data from National Oceanic and Atmospheric Administration (NOAA) survey H12003 along the Delmarva Peninsula, Delaware, Maryland, and Virginia, showing A, a 1-meter-per-pixel grid containing data gaps within areas shallower than approximately 10 meters, and $B$, a 5-meter-per-pixel grid generated by the U.S. Geological Survey through interpolation and resampling of the NOAA data for use in regional geologic mapping studies. Map location is shown on figure 5. MLLW, mean lower low water. Not for navigational use. 


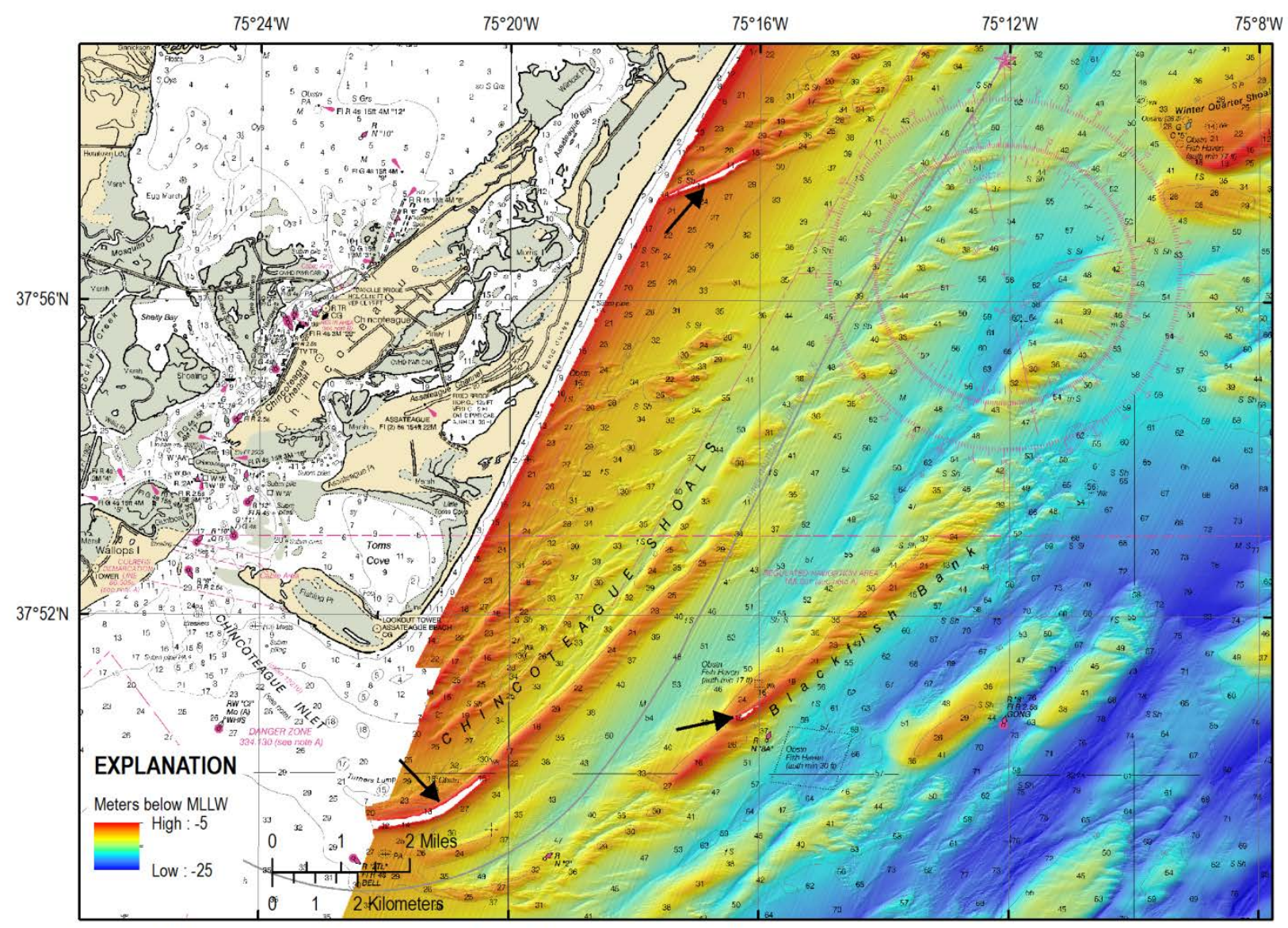

Base Credit: National Oceanic and Atmospheric Administration electronic nautical chart 12211, 2013

Figure 4. Map of resampled, interpolated bathymetric data from National Oceanic and Atmospheric Administration surveys H12003, H12092, H12093, and H12094 along the Delmarva Peninsula, Delaware, Maryland, and Virginia, showing data gaps (black arrows) across the tops of shoals that were not filled in after five iterations of nearest neighbor interpolation. These gaps were left unfilled in order to avoid introducing erroneous depth values through interpolation. Map location is shown on figure 5 . Not for navigational use. MLLW, mean lower low water. 


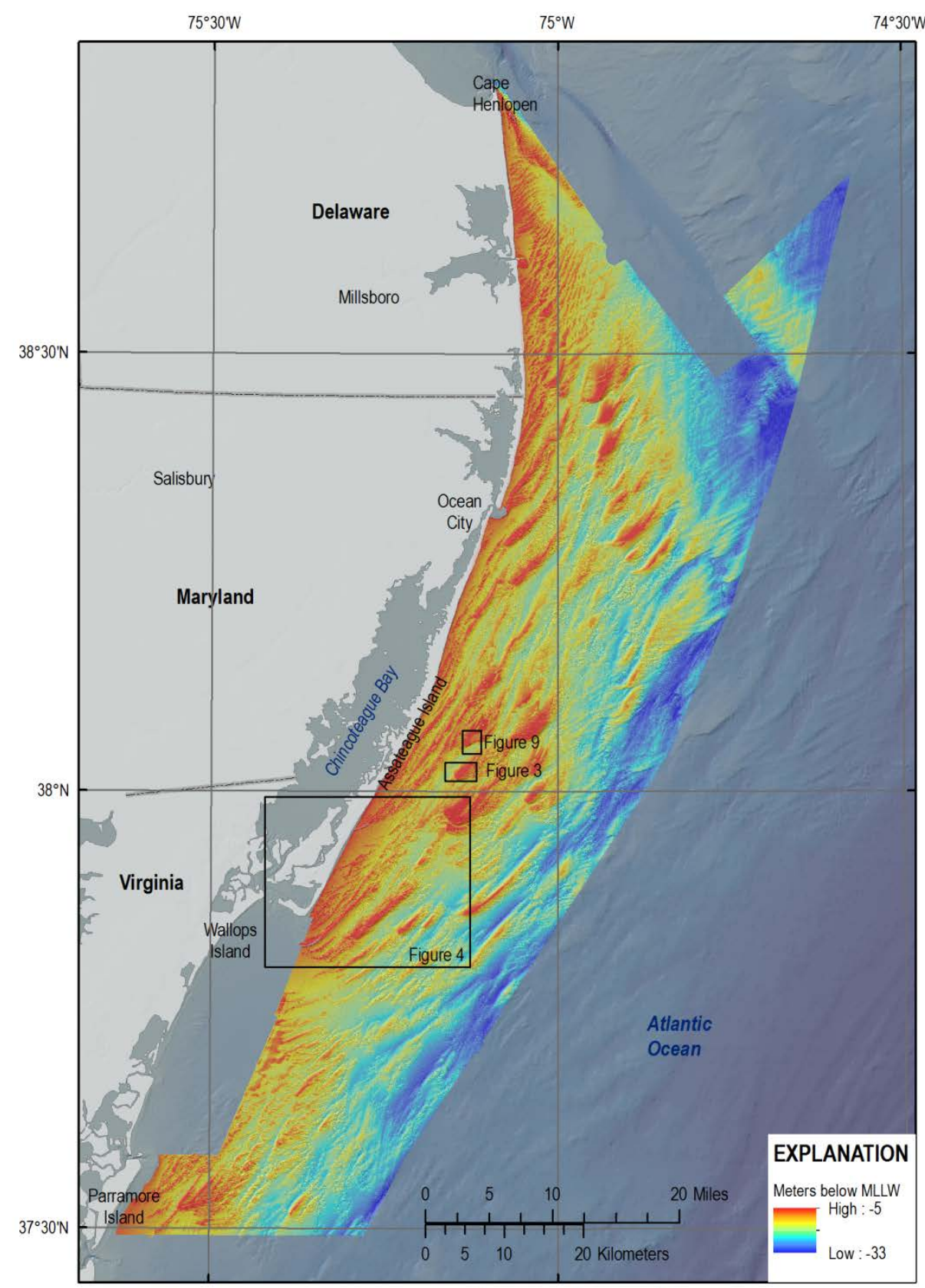

Base Credit: Shorelines and waterways from the Global Self-consistent, Hierarchical, High-resolution Geography Database (GSHHG). Shaded relief from National Oceanic and Atmospheric Administration U.S. Coastal Relief Model.

Figure 5. Map showing the interpolated bathymetric data along the Delmarva Peninsula, Delaware, Maryland, and Virginia, in a 5-meter-per-pixel grid. Bathymetric data were merged and small gaps filled between adjacent survey lines to create a regional seamless bathymetric grid to use in regional geologic framework studies. Not for navigational use. MLLW, mean lower low water. 


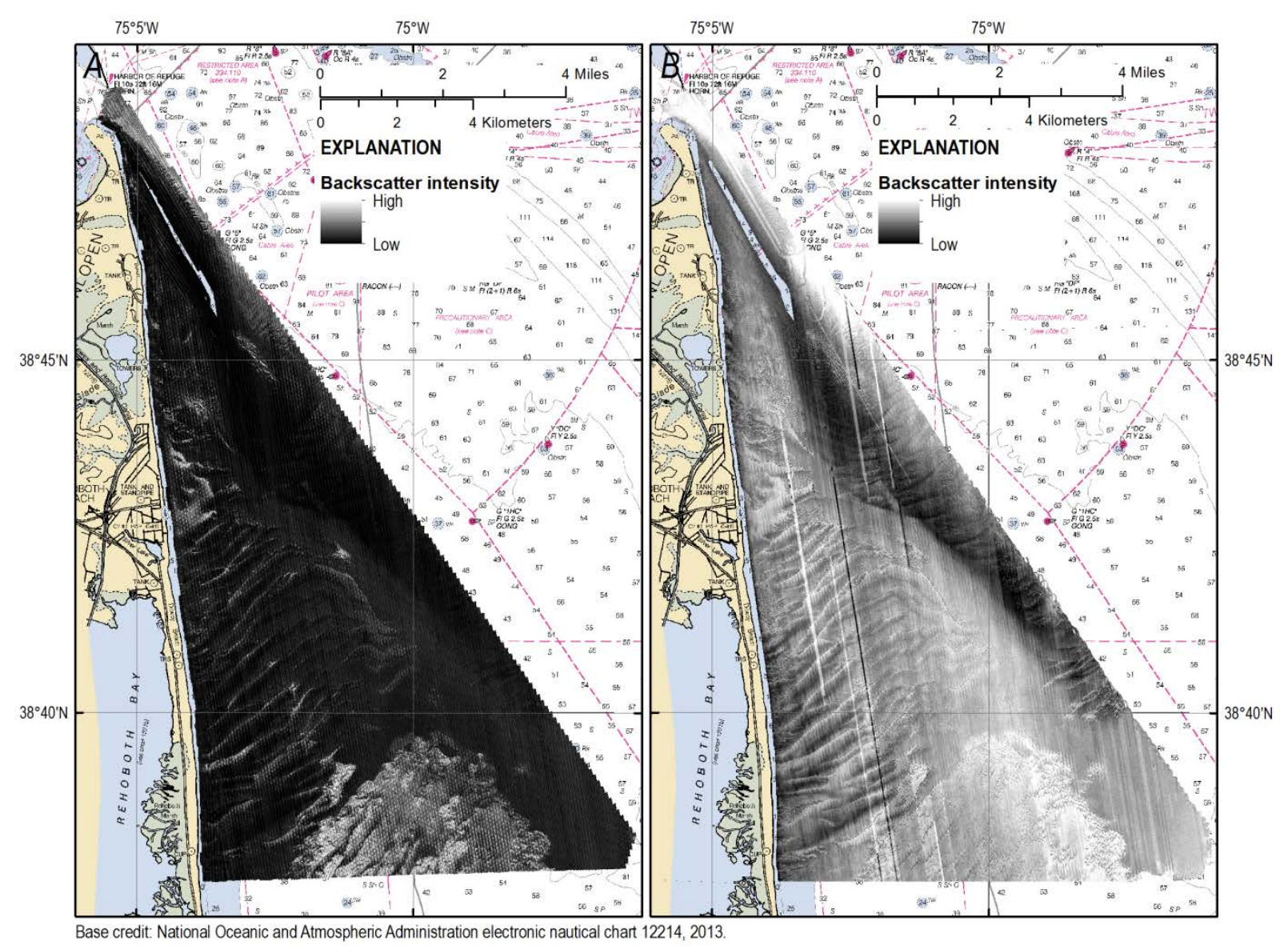

Figure 6. Map of National Oceanic and Atmospheric Administration survey H11647 along the Delmarva Peninsula, Delaware, Maryland, and Virginia, showing a backscatter mosaic collected A, with a Klein 3000 sidescan sonar published as a georeferenced tagged image format file and $B$, with a Reson 8101multibeam echosounder system (MBES) and processed by U.S. Geological Survey. Both sidescan and multibeam backscatter data are able to resolve a series of shoreface-attached ridges; however, there appears to be more dynamic range in the multibeam data. Some banding artifacts are present in the MBES data. These are thought to be introduced by gain changes during acquisition. Location of survey is shown on figure 1. 


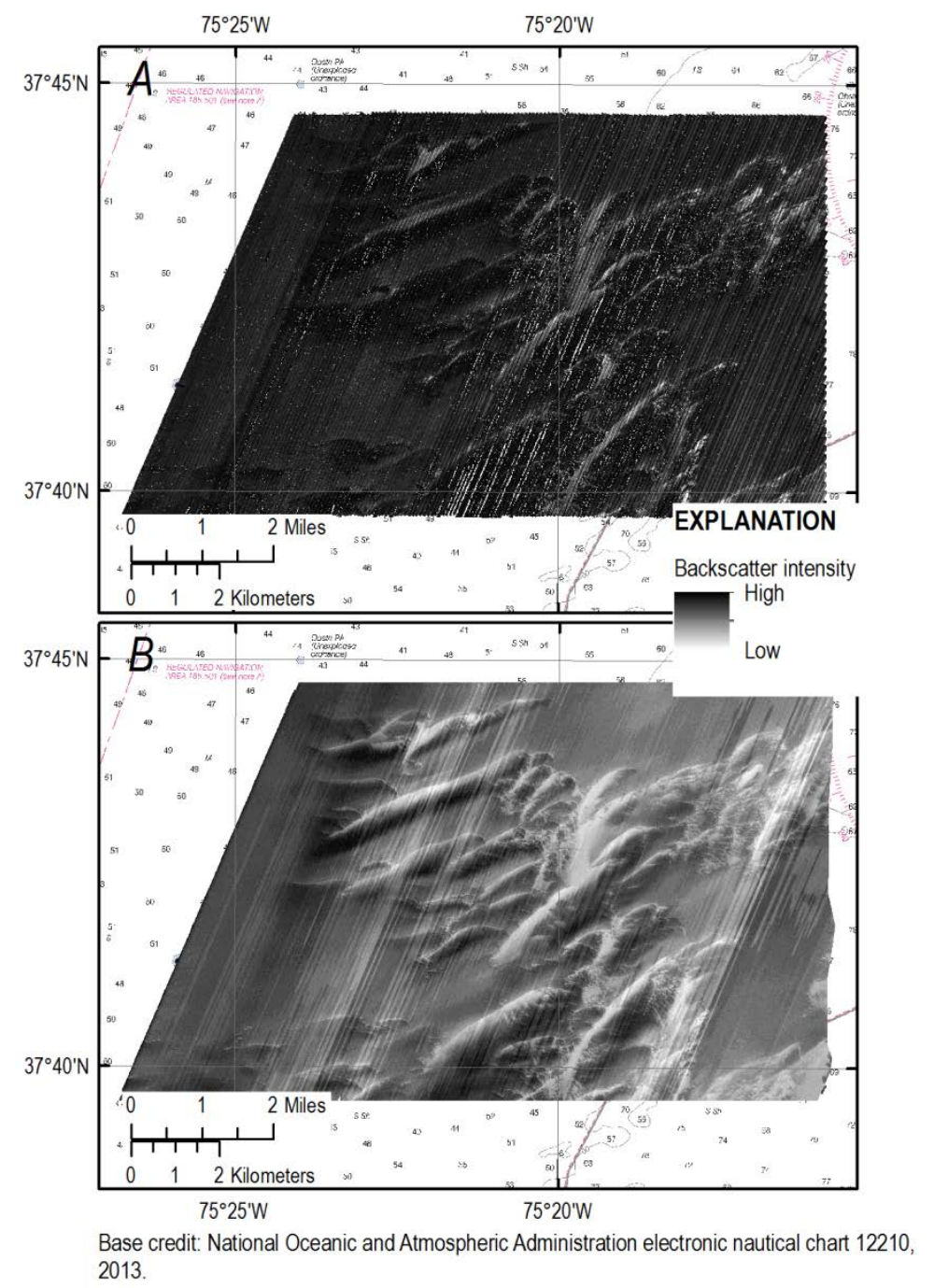

Figure 7. Map of National Oceanic and Atmospheric Administration survey H12160 along the Delmarva Peninsula, Delaware, Maryland, and Virginia, showing a backscatter mosaic collected A, with a Klein 3000 sidescan sonar published as a layer in a georeferenced portable document format map and $B$, with a Reson 7125 multibeam system and processed by U.S. Geological Survey. The sidescan sonar data have some nadir artifacts and data dropouts, which create striping in the mosaic. Multibeam data contain banding artifacts, but overall less striping than the sidescan sonar data. Location of survey is shown on figure 1. 


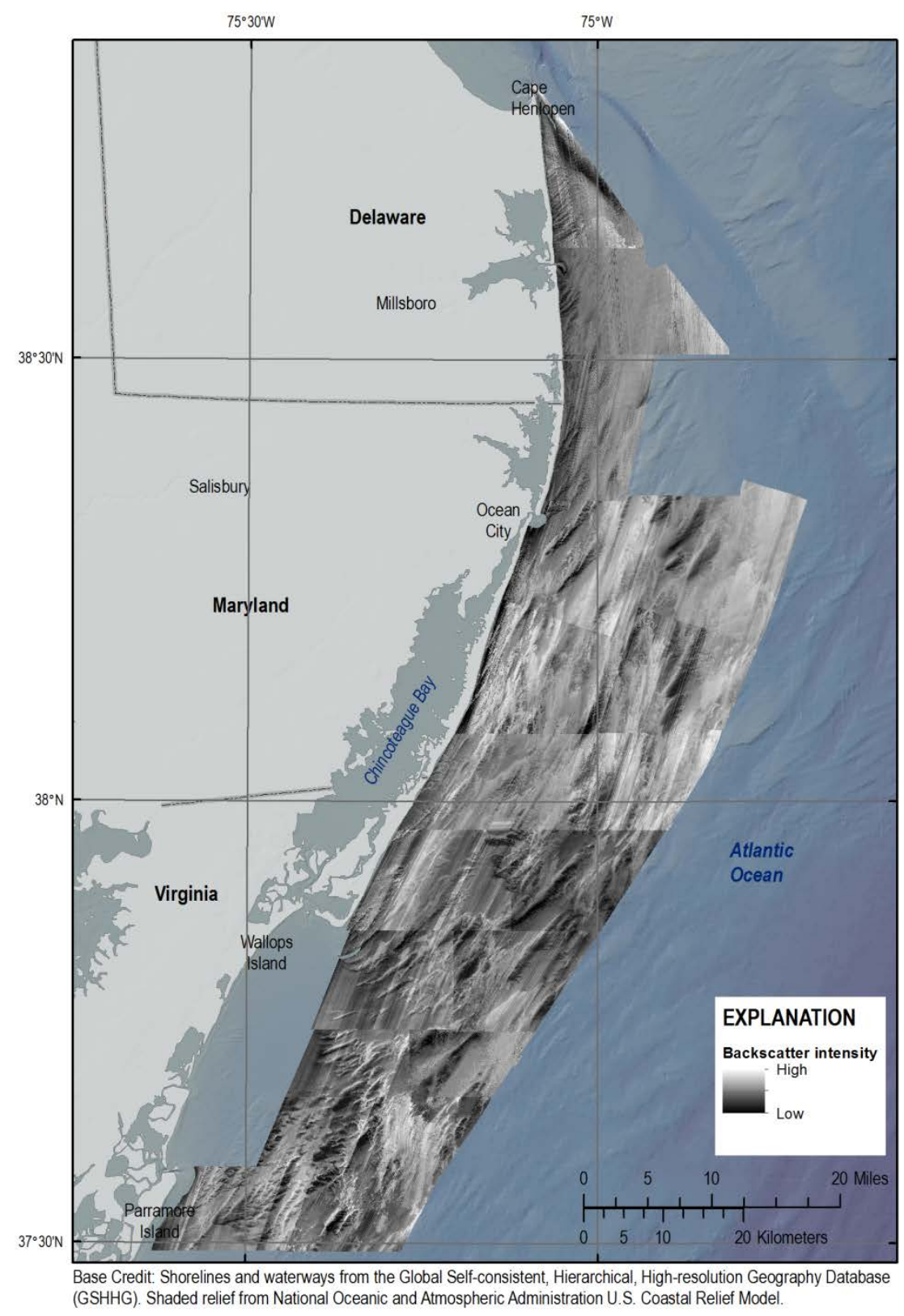

Figure 8. Map showing 2-meter-per-pixel resolution multibeam backscatter images for 20 hydrographic surveys along the Delmarva Peninsula, Delaware, Maryland, and Virginia, collected by Science Applications International Corporation for the National Oceanic and Atmospheric Administration and reprocessed by the U.S. Geological Survey to create a regional backscatter mosaic for geologic framework investigations. Not for navigational use. 


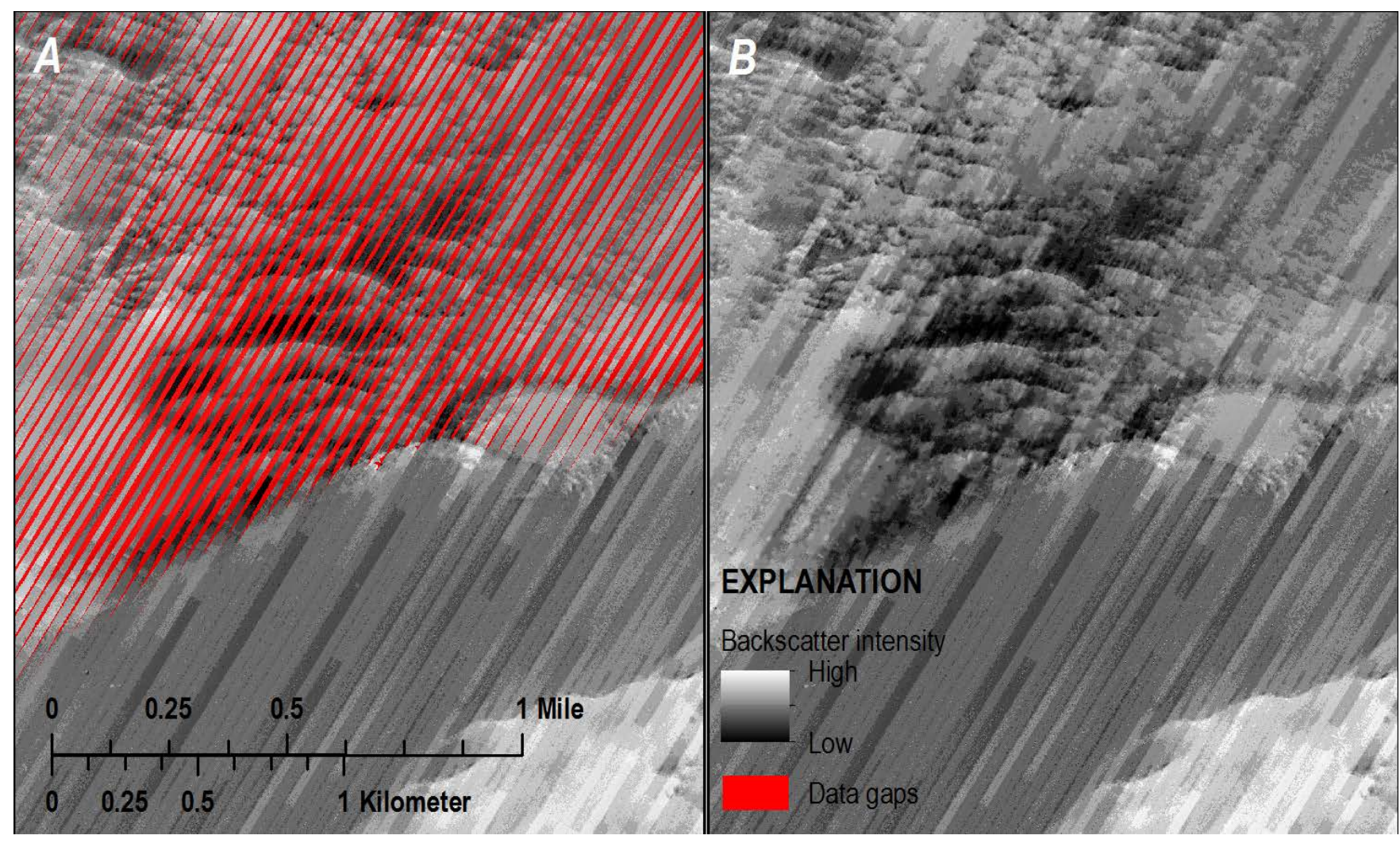

Figure 9. Images of acoustic backscatter mosaics from National Oceanic and Atmospheric Administration survey H12003 along the Delmarva Peninsula, Delaware, Maryland, and Virginia, $A$, uninterpolated to show real data gaps (in red) between shallow water lines and $B$, interpolated output from MathWorks MATLAB that removes null-data gaps and creates a seamless backscatter image. Map location is shown on figure 5. Not for navigational use. 
Table 1. National Oceanic and Atmospheric Administration hydrographic surveys along the Delmarva Peninsula, Delaware, Maryland, and Virginia, processed for multibeam backscatter. Sidescan sonar mosaics listed as not available through the IMS may be available by request through NGDC.

[Hydrographic survey data were processed with FMGeocoder Toolbox of Quality Positioning Service’s Fledermaus. Click on a survey number to retrieve the survey descriptive report; descriptive reports are listed in the Selected References section of this report. NGDC, National Geophysical Data Center ; IMS, Internet Mapping Server; km, kilometers; km², square kilometers; GeoTIFF, georeferenced tagged interface format file; Geo PDF, georeferenced portable document format]

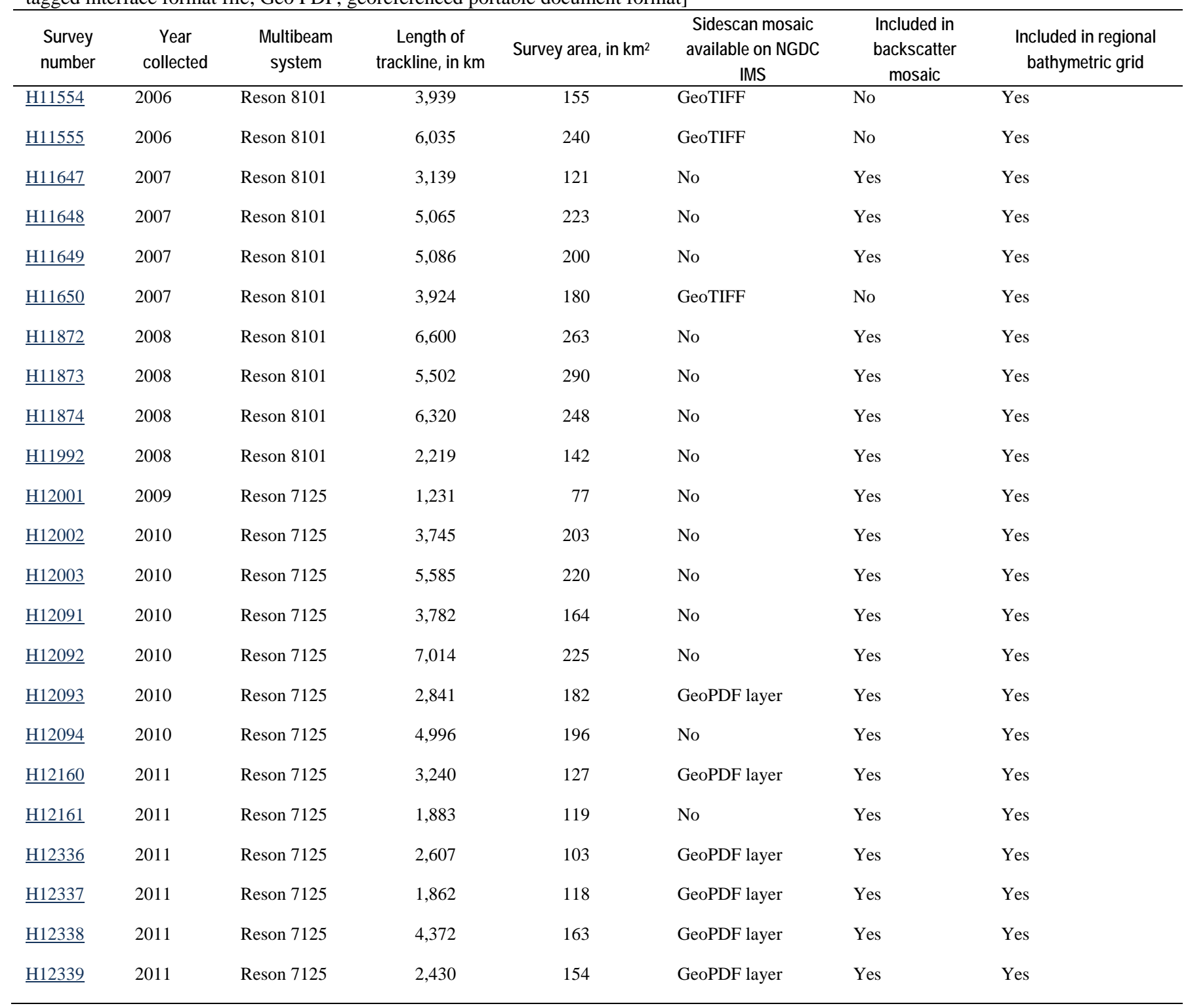


Table 2. Advantages and disadvantages of multibeam echosounder and sidescan sonar backscatter. [Based on Hewitt and others (2010). Advantages are shown highlighted in green, and disadvantages, in red]

Multibeam echosounder backscatter

Bathymetry and backscatter are collected simultaneous with a multibeam echosounder system (MBES), so only one instrument is necessary

Multibeam backscatter can be radiometrically (travel path) and geometrically (seafloor topography) corrected because the area of insonification is known in three dimensions

Multibeam backscatter range is limited by water depth in the same way that multibeam bathymetry is limited; surveying efficiency is not as good with an MBES when compared with a sidescan sonar system

With the development of GeoCoder processing algorithms, MBES backscatter processing is largely managed by a computer with limited time invested by a user

\section{Sidescan sonar backscatter}

A towed sidescan system can introduce significant positioning errors associated with cable-out and currents; this may lead to offsets in mosaics between adjacent survey lines

Sidescan sonar data can contain offsets and shadows associated with features because there is no correction of bathymetry and the seafloor is assumed to be flat

The much broader swath width (100 to 200 -meter range in shallow water) of a sidescan sonar system can greatly increase surveying efficiency for shallow water (less than 50 meter) surveys where 100 percent bathymetric coverage is not needed

Processing can be time consuming, requiring user input for many processing steps including bottom detection, corrections, and positional offsets 
For more information concerning this report, contact

\section{Director}

Woods Hole Coastal and Marine Science Center

U.S. Geological Survey

384 Woods Hole Road

Quissett Campus

Woods Hole, MA 02543-1598

WHSC_science_director@usgs.gov

Telephone: (508) 548-8700 or (508) 457-2200

or visit our Web site at

http://woodshole.er.usgs.gov/ 
